SOI: $1.1 /$ TAS $\quad$ DOI: $10.15863 /$ TAS

International Scientific Journal Theoretical \& Applied Science

p-ISSN: 2308-4944 (print) $\quad$ e-ISSN: 2409-0085 (online)

Year: $2016 \quad$ Issue: 1 Volume: 33

Published: $30.01 .2016 \quad \underline{\text { http://T-Science.org }}$

SECTION 9. Chemistry and chemical technology.
Oleg Ivanovich Yurchenko

Doctor of chemical sciences, Professor, Department of Chemistry,

V. N. Karazin Kharkiv National University, Ukraine yurchenko@karazin.ua

Olga Sergeevna Kalinenko assistant, Department of Medical and Bioorganic Chemistry,

Kharkov National Medical University, Ukraine ok150388@mail.ru

Aleksandr Nikolaevich Baklanov

Doctor of chemical sciences, Professor, Department of Chemistry,

V. N. Karazin Kharkiv National University, Ukraine baklanov227@mail.ru

Elena Aleksandrovna Belova

Candidate of chemical sciences, Docent, Department of Chemical and Food Technology, Ukrainian Engineering and Pedagogical Academy, Ukraine

Larisa Vladimirovna Baklanova Candidate of chemical sciences, Docent, Department of Occupational Health and Environmental Safety,

Ukrainian Engineering and Pedagogical Academy, Ukraine baklanovalarisa@ya.ru

\title{
ULTRASOUND IN THE DETERMINATION OF LEAD, COPPER AND CADMIUM IN THE SUGAR AND PRODUCTS ON ITS BASIS
}

Abstract: The use of the simultaneous action of two ultrasonic frequencies and pulsed ultrasound in the analysis of sugar-based products for lead, copper and cadmium have been studied. It is shown that the use of twofrequency ultrasound improves the metrological performance analysis as compared to use only a single ultrasonic frequency. The technique of atomic absorption determination of lead, copper and cadmium with sensitivity 0,067, 0,013 i 0,004 mg / $\mathrm{kg}$ respectively have been proposed.

Key words: sugar, dual-frequency ultrasound, the metrological characteristics.

Language: Russian

Citation: Yurchenko OI, Kalinenko OS, Baklanov AN, Belova EA, Baklanova LV (2016) ULTRASOUND IN THE DETERMINATION OF LEAD, COPPER AND CADMIUM IN THE SUGAR AND PRODUCTS ON ITS BASIS. ISJ Theoretical \& Applied Science, 01 (33): 158-163.

Soi: http://s-o-i.org/1.1/TAS-01-33-28 Doi: crossef http://dx.doi.org/10.15863/TAS.2016.01.33.28

\section{УЛЬТРАЗВУК В ОПРЕДЕЛЕНИИ СВИНЦА, МЕДИ И КАДМИЯ В САХАРЕ И ПРОДУКТАХ НА ЕГО ОСНОВЕ}

Аннотация: Изучено использование одновременного воздействия ультразвука двух частот, а также импульсного ультразвука в анализе сахара и продуктов на его основе на содержание свинца, меди и кадмия. Показано, что использование двухчастотного ультразвука позволяет улучшить метрологические характеристики результатов анализа по сравнению с использованием ультразвука только одной частоты. Предложена методика атомно-абсорбционного определения свинца, меди и кадмия с чувствительностью определения 0,067, 0,013 и 0,004 мг/кг соответственно.

Ключевые слова: сахар, двухчастотный ультразвук, метрологические характеристики.

Введение. При анализе сахара на содержание свинца, меди и кадмия используется сухая минерализация, заключающаяся в обугливании продукта на электроплитке с термообработкой в муфельной печи при температуре от 150 до $450{ }^{\circ} \mathrm{C}$ более 30 ч с последующим атомно-абсорбционным 
или полярографическим определением. При этом возможны значительные потери определяемых элементов, достигающие 30 \%. Для устранения потерь свинца, меди и кадмия при анализе сахара, перед минерализацией, его смачивают 2 моль/л серной кислотой, это загрязняет анализируемый продукт примесями определяемыми элементами [1, 2].

Авторами работ [3, 4] предложена методика анализа сахара на содержание токсичных элементов с использованием автоклавной пробоподготовки. При этом проба сахара массой 2,00 г, взвешенной с погрешностью не более 0,0002 г, заливалась смесью 8 частей азотной кислоты с 1 частью пероксида водорода на 40 мин. Затем систему нагревали в автоклаве при температуре $160{ }^{\circ} \mathrm{C}-1$ ч, при $180{ }^{\circ} \mathrm{C}-2$ ч и при $200{ }^{\circ} \mathrm{C}-1$ ч. Определение свинца, меди и кадмия проводили методом инверсионной вольтамперометрии. Относительное стандартное отклонение результатов определения не превышало 0,12 [3, 4].

Известно применение экстрагирования свинца, меди и кадмия непосредственно из растворов сахара в виде диэтилдитиокарбаматов в метилизобутилкетон или хлороформ [5]. Однако раствор сахара должен иметь концентрацию не более 15 г/л, при этом степень извлечения не превышает $80 \%$. Для перевода соединений свинца, меди и кадмия в растворе сахара в кинетически лабильные формы, анализируемый раствор предварительно кипятят в течение 20 мин с уксусной кислотой [5].

Для ускорения процесса перевода соединений свинца, меди и кадмия в кинетически лабильные соединения авторы работы [6] использовали воздействие ультразвука (У3) частотой 20-44 кГц, интенсивностью не менее $10 \mathrm{BT} / \mathrm{cm}^{2}$ в течение 2,0-3,5 мин. При этом, возможно количественное экстрагирование меди и цинка из растворов сахара с концентрацией до 75 г/л со степенью извлечения 90-92 \%. Однако, использование мощного УЗ, интенсивностью > 10 $\mathrm{BT} / \mathrm{cm}^{2}$, не обеспечивало удовлетворительных метрологических характеристик результатов анализа, $\mathrm{Sr}>0,10$ [6] .

В работе [7] описано использование одновременного действия УЗ высокой и низкой частот при пробоподготовке поваренной соли для определения токсических элементов.

Целью данной работы является исследование возможности использования одновременного действия УЗ высокой и низкой частот при пробоподготовке для атомноабсорбционного определения свинца, меди и кадмия в сахаре и продуктах на его основе.

Экспериментальная часть. УЗ обработку проводили в химическом реакторе, конструкция которого позволяет одновременно действовать на раствор исследуемого УЗ частотой 18-100 кГц и 1,0-5,0 МГц [7]. Источниками У3 служили магнитострикционные и пьезоэлектрические излучатели с рабочими частотами от 18 кГц до 5,0 МГц, подключаемые к ламповому генератору 24-УЗГИ-К-1,2 (Россия) и к ультразвуковому модернизированному диспергатору УЗДН - 1М (Украина). Использовали атомно- абсорбционный спектрометр ААС -3 (Германия ).

Методика анализа. 100 г сахара (или продукта на его основе), взвешенной с погрешностью не более 0,0002 г, растворяют в бидистиллированной воде. Объем раствора доводят бидистиллированной водой до 1000 мл и воздействуют УЗ частотой 18-100 кГц и УЗ частотой 1,0-1,5 МГц, при этом интенсивность низкочастотного УЗ должна быть 1,5-2,5 Вт/ $\mathrm{cm}^{2}$, а высокочастотного - $1,5-3,0 \quad \mathrm{BT} / \mathrm{cm}^{2}$, время воздействия УЗ должно быть 1 - 3 мин.

Полученный раствор переносят в делительную воронку, приливают 3 моль/л раствора $\mathrm{NaOH}$ до $\mathrm{pH} 9,5$ мл $3 \%$ раствора диэтилдитиокарбамината натрия, 10 мл хлороформа и экстрагируют микроэлементы на протяжении 7 мин с применением механического встряхивателя (120 встряхиваний в мин). После разделения слоев, экстракт сливают в фарфоровую чашку. Экстракцию повторяют и экстракты объединяют. Далее экстракты осторожно упаривают на электроплитке в присутствии азотной кислоты (1:1).

Сухой остаток растворяют в 5 мл соляной кислоты (1:1). В полученном растворе определяют содержание свинца, меди и кадмия пламенным атомно-абсорбционным методом. Условия определения свинца, меди и кадмия: длина волны 283,3, 324,7, 228,8 нм, величина тока ламп "Narva" - 5, 3 и 3 мА, ширина щели монохроматора - 0,20 мм, расход ацетилена - 2, воздуха - 13 л/хв. Параллельно проводили "холостой" опыт для определения примесей металлов в используемых реагентах, а также опыты без действия УЗ.

Чувствительность определения свинца, меди и кадмия - 0,067, 0,013 и 0,004 мг/кг соответственно.

Результаты и их обсуждение. Предварительная обработка УЗ растворов сахара позволяет количественно экстрагировать свинец, медь и кадмий из растворов с концентрацией caxapa до 100 г/л. При этом, время экстрагирования может быть сокращено с 8-10 до 5-7 мин по сравнению с использованием УЗ одной частоты за счет перехода свинца, меди и кадмия в более кинетически лабильные соединения (табл.1). 
Таблица 1

Влияние концентрации сахара на степень извлечения ( $R$ ) свинца, меди и кадмия и на время экстрагирования $(\mathrm{n}=6, \mathrm{P}=\mathbf{0 , 9 5 )}$

\begin{tabular}{|c|c|c|c|c|c|c|c|c|c|}
\hline \multirow{3}{*}{$\begin{array}{c}\text { Концентрация } \\
\text { сахара, г/л }\end{array}$} & \multicolumn{9}{|c|}{$\begin{array}{c}\text { Степень извлечения (R), \% ; } \\
\text { время экстрагирования (t), мин }\end{array}$} \\
\hline & \multicolumn{3}{|c|}{$\mathrm{Pb}$} & \multicolumn{3}{|c|}{$\mathrm{Cu}$} & \multicolumn{3}{|c|}{$\mathrm{Cd}$} \\
\hline & $\mathrm{R} \pm \varepsilon$ & $\mathrm{Sr}$ & $\mathrm{t}^{* *}$ & $\mathrm{R}$ & $\mathrm{Sr}$ & $\mathrm{t}^{* * *}$ & $\mathrm{R}$ & $\mathrm{Sr}$ & $\mathrm{t}^{* *}$ \\
\hline 40 & $97,2 \pm 5,4$ & 0,06 & 5 & $99,0 \pm 6,4$ & 0,07 & 5 & $98,1 \pm 6,4$ & 0,07 & 5 \\
\hline $40^{*}$ & $94,1 \pm 6,1$ & 0,07 & 10 & $98,3 \pm 7,3$ & 0,08 & 8 & $96,3 \pm 8,0$ & 0,09 & 10 \\
\hline 50 & $97,0 \pm 7,2$ & 0,08 & 5 & $99,1 \pm 5,5$ & 0,06 & 5 & $98,2 \pm 5,5$ & 0,06 & 5 \\
\hline $50^{*}$ & $90,4 \pm 7,5$ & 0,09 & 10 & $96,4 \pm 7,1$ & 0,08 & 8 & $92,3 \pm 6,0$ & 0,07 & 10 \\
\hline $50^{\Omega}$ & - & - & 10 & - & - & 10 & - & - & 10 \\
\hline $50^{\Omega \Omega}$ & - & - & 10 & - & - & 10 & - & - & 10 \\
\hline 60 & $95,4 \pm 6,2$ & 0,07 & 6 & $98,4 \pm 5,5$ & 0,06 & 5 & $96,4 \pm 5,4$ & 0,06 & 5 \\
\hline $60^{*}$ & $80,7 \pm 6,7$ & 0,09 & 10 & $87,4 \pm 6,5$ & 0,08 & 9 & $83,5 \pm 6,2$ & 0,08 & 10 \\
\hline 70 & $94,3 \pm 7,0$ & 0,08 & 5 & $96,3 \pm 6,4$ & 0,06 & 5 & $95,1 \pm 6,2$ & 0,07 & 5 \\
\hline 80 & $93,4 \pm 6,9$ & 0,08 & 5 & $97,2 \pm 5,4$ & 0,06 & 5 & $94,3 \pm 6,1$ & 0,07 & 5 \\
\hline 90 & $93,5 \pm 6,9$ & 0,08 & 7 & $95,1 \pm 5,4$ & 0,06 & 5 & $94,2 \pm 6,1$ & 0,07 & 5 \\
\hline 100 & $92,6 \pm 6,9$ & 0,08 & 7 & $94,1 \pm 5,3$ & 0,06 & 5 & $93,3 \pm 6,1$ & 0,07 & 5 \\
\hline 110 & $81,8 \pm 6,8$ & 0,09 & 7 & $87,6 \pm 7,3$ & 0,09 & 5 & $84,7 \pm 7,9$ & 0,10 & 5 \\
\hline 120 & $74,6 \pm 6,9$ & 0,10 & 7 & $80 \pm 6,7$ & 0,09 & 5 & $76,5 \pm 7,1$ & 0,10 & 5 \\
\hline
\end{tabular}

* Использовали УЗ с частотой $22 \kappa$ Ки, интенсивностью $12 \mathrm{Bm} / \mathrm{cm}^{2}$ в течение 5 мин.

Применяли одновременное воздействие УЗ с частотой $22 \kappa \Gamma и$, интенсивностью $2,0 \mathrm{Bm} / \mathrm{cm}^{2} u$ ультразвука с частотой 1,0 МГи, интенсивностью 2,5 $\mathrm{Bm} / \mathrm{cm}^{2}$ на протяжение 2 мин.

*** Использовали оптимальное время экстрагирование, обеспечивающее максимально возможную степень извлечения свиниа, меди и кадмия.

^Опыты проводили в условиях невозможности протекания звукохимических реакций, при насыщении проб $\mathrm{CO}_{2}[8]$.

${ }^{\Omega \Omega}$ Опьты проводили без использования УЗ, после предварительного кипячения проб с уксусной кислотой согласно [5].

При озвучивании водных растворов насыщенных $\mathrm{CO}_{2}$, звукохимические реакции не идут, поскольку $\mathrm{CO}_{2}$ проникает в кавитационную полость уже на ранней стадии ее развития и препятствует электрическому пробою или эффективно дезактивирует возбужденные состояния $[7,8]$.

При проведении опытов в условиях невозможности протекания звукохимических реакций, положительного эффекта не наблюдалось. Очевидно, что в основе наблюдаемого эффекта лежит протекание звукохимических реакций, приводящих к определенным структурным изменениям раствора $[7,8]$. В пользу этого предположения также говорит тот факт, что переход свинца, меди и кадмия в кинетически лабильные соединения кипячением проб с уксусной кислотой к повышению степени извлечения микроэлементов не привел (табл.1).

Изменение частоты низкочастотного УЗ от 18 до 100 кГц на степень извлечения свинца, меди и кадмия практически не влияла (табл.2). Сравнение результатов, полученных с использованием высокочастотного УЗ с частотой 1-5 Мгц показало, что лучшие результаты были получены при использовании УЗ с частотой 1,02,5 Мгц (табл. 3). При этом интенсивность

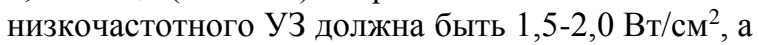
высокочастотного - 2,5-4,0 Вт/см² (табл. 4). Время действия УЗ должно быть не менее 1 мин (табл. 4). 


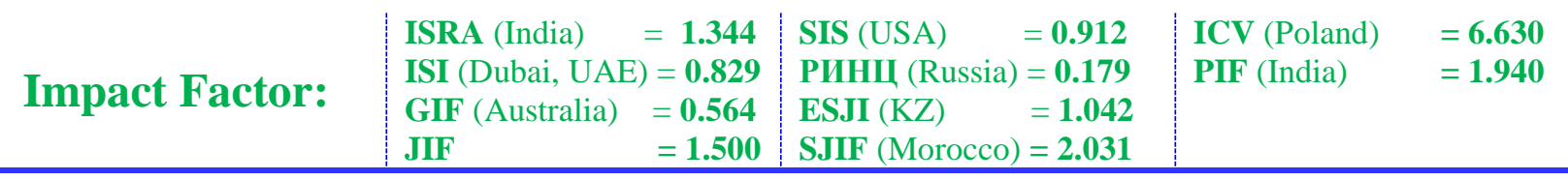

Таблица 2

Влияние частоты низкочастотного УЗ на степень извлечения $(\mathbf{R})$ свинца, меди и кадмия из растворов сахара $(n=6, P=0,95)$

\begin{tabular}{|c|c|c|c|c|c|c|}
\hline \multirow{2}{*}{ Частота, кГц } & \multicolumn{6}{|c|}{ Найдено микроэлементов (R, \%); $\mathrm{Sr}$} \\
\cline { 2 - 7 } & \multicolumn{2}{|c|}{ Свинец } & \multicolumn{2}{c|}{ Медь Кадмй } \\
\cline { 2 - 6 } & $\mathrm{R} \pm \varepsilon, \%$ & $\mathrm{Sr}$ & $\mathrm{R} \pm \varepsilon, \%$ & $\mathrm{Sr}$ & $\mathrm{R} \pm \varepsilon, \%$ & $\mathrm{Sr}$ \\
\hline 18 & $90,4 \pm 6,7$ & 0,08 & $93,4 \pm 6,9$ & 0,08 & $93,3 \pm 6,9$ & 0,08 \\
\hline 22 & $92,6 \pm 6,8$ & 0,08 & $94,1 \pm 5,2$ & 0,06 & $93,3 \pm 6,1$ & 0,07 \\
\hline 44 & $92,4 \pm 6,9$ & 0,08 & $93,4 \pm 6,1$ & 0,07 & $93,2 \pm 6,0$ & 0,07 \\
\hline 50 & $91,3 \pm 6,8$ & 0,08 & $93,1 \pm 6,0$ & 0,07 & $92,4 \pm 6,0$ & 0,07 \\
\hline 60 & $90,3 \pm 6,7$ & 0,08 & $92,4 \pm 6,0$ & 0,07 & $92,4 \pm 6,0$ & 0,07 \\
\hline 80 & $90,4 \pm 6,7$ & 0,08 & $91,3 \pm 5,9$ & 0,07 & $91,4 \pm 5,9$ & 0,07 \\
\hline 100 & $89,4 \pm 6,6$ & 0,08 & $91,2 \pm 5,9$ & 0,07 & $90,4 \pm 6,7$ & 0,08 \\
\hline 110 & $78,5 \pm 6,5$ & 0,09 & $84,6 \pm 7,1$ & 0,09 & $82,3 \pm 6,9$ & 0,09 \\
\hline
\end{tabular}

Частота высокочастотного УЗ 1,0 МГц, интенсивность - $2,5 \mathrm{BT} / \mathrm{cm}^{2}$. Интенсивность низкочастотного УЗ - $2 \mathrm{BT} / \mathrm{cm}^{2}$. Время воздействия УЗ - 2 хв. Использовали раствор сахара с концентрацией 100 г/л.

Таблица 3

Влияние частоты высокочастотного УЗ на степень извлечения (R) свинца, меди и кадмия из растворов сахара $(n=6, P=0,95)$

\begin{tabular}{|c|c|c|c|c|c|c|}
\hline \multirow{2}{*}{ Частота, МГц } & \multicolumn{6}{|c|}{ Найдено микроэлементов $(\mathrm{R}, \%) ; \mathrm{Sr}$} \\
\cline { 2 - 7 } & \multicolumn{2}{|c|}{ Свинец } & \multicolumn{2}{c|}{ Медь } & \multicolumn{3}{c|}{ Кадмий } \\
\cline { 2 - 7 } & $\mathrm{R} \pm \varepsilon, \%$ & $\mathrm{Sr}$ & $\mathrm{R} \pm \varepsilon, \%$ & $\mathrm{Sr}$ & $\mathrm{R} \pm \varepsilon, \%$ & 0,07 \\
\hline 1 & $92,6 \pm 6,9$ & 0,08 & $94,1 \pm 5,2$ & 0,06 & $93,3 \pm 6,1$ & 0,07 \\
\hline 2 & $91,3 \pm 6,8$ & 0,08 & $93,4 \pm 5,2$ & 0,06 & $92,3 \pm 6,0$ & 0,07 \\
\hline 2,5 & $90,2 \pm 6,7$ & 0,08 & $90,4 \pm 5,9$ & 0,07 & $90,1 \pm 6,7$ & 0,08 \\
\hline 3 & $86,3 \pm 6,4$ & 0,08 & $89,6 \pm 5,8$ & 0,07 & $87,5 \pm 6,5$ & 0,08 \\
\hline 4 & $80,5 \pm 6,0$ & 0,08 & $78,4 \pm 5,8$ & 0,08 & $69,4 \pm 5,8$ & 0,09 \\
\hline 5 & $45,4 \pm 3,4$ & 0,08 & $43,6 \pm 3,2$ & 0,08 & $38,5 \pm 3,2$ & 0,09 \\
\hline
\end{tabular}

Частота низкочастотного УЗ 22,0 кГц, интенсивность - $2 \mathrm{~B} / \mathrm{cm}^{2}$. Интенсивность высокочастотного УЗ - 2,5 $\mathrm{Bт} / \mathrm{cm}^{2}$. Время воздействия УЗ - 2 мин. Использовали раствор сахара концентрацией 100 г/л.

Таблица 4

Влияние интенсивности ультразвука на степень извлечения (R) микроэлементов свинца, меди и кадмия из растворов сахара $(n=6, P=0,95)$

\begin{tabular}{|c|c|c|c|c|c|c|c|c|c|c|c|c|}
\hline \multirow{3}{*}{$\begin{array}{c}\text { Интенсивность } \\
\text { низкочастотного } \\
\text { У3, Вт/см }{ }^{2} \\
\end{array}$} & \multicolumn{12}{|c|}{ Интенсивность УЗ высокой частоты, Вт/см² } \\
\hline & \multicolumn{2}{|c|}{2,0} & \multicolumn{2}{|c|}{2,5} & \multicolumn{2}{|c|}{3,0} & \multicolumn{2}{|c|}{4,0} & \multicolumn{2}{|c|}{5,0} & \multicolumn{2}{|c|}{6,0} \\
\hline & $\mathrm{R} \pm \varepsilon, \%$ & $\mathrm{Sr}$ & $\mathrm{R} \pm \varepsilon, \%$ & $\mathrm{Sr}$ & $\mathrm{R} \pm \varepsilon, \%$ & $\mathrm{Sr}$ & $\mathrm{R} \pm \varepsilon, \%$ & $\mathrm{Sr}$ & $\mathrm{R} \pm \varepsilon, \%$ & $\mathrm{Sr}$ & $\mathrm{R} \pm \varepsilon, \%$ & $\mathrm{Sr}$ \\
\hline \multicolumn{13}{|c|}{ Свинец } \\
\hline 1,0 & $\begin{array}{c}65,5 \pm \\
5,5\end{array}$ & 0,09 & $\begin{array}{c}66,5 \pm \\
5,5\end{array}$ & 0,09 & $\begin{array}{c}71,4 \pm \\
5,3\end{array}$ & 0,08 & $\begin{array}{c}74,3 \pm \\
5,5\end{array}$ & 0,08 & \begin{tabular}{|c|}
$75,3 \pm$ \\
6,3
\end{tabular} & 0,09 & $\begin{array}{c}77,1 \pm \\
6,4\end{array}$ & 0,09 \\
\hline 1,5 & $\begin{array}{c}85,2 \pm \\
6,3\end{array}$ & 0,08 & $\begin{array}{c}91,2 \pm \\
6,8\end{array}$ & 0,08 & $\begin{array}{c}92,3 \pm \\
6,8\end{array}$ & 0,08 & $\begin{array}{c}91,3 \pm \\
6,8\end{array}$ & 0,08 & $\begin{array}{c}83,4 \pm \\
7,0\end{array}$ & 0,09 & $\begin{array}{c}80,3 \pm \\
6,7\end{array}$ & 0,09 \\
\hline 2,0 & $\begin{array}{c}89,1 \pm \\
6,6\end{array}$ & 0,08 & $\begin{array}{c}92,6 \pm \\
6,9\end{array}$ & 0,08 & $\begin{array}{c}93,4 \pm \\
6,9\end{array}$ & 0,08 & $\begin{array}{c}91,2 \pm \\
6,8\end{array}$ & 0,08 & $\begin{array}{c}84,3 \pm \\
7,0\end{array}$ & 0,09 & $\begin{array}{c}82,4 \pm \\
7,6\end{array}$ & 0,10 \\
\hline 2,5 & $\begin{array}{c}89,3 \pm \\
6,6\end{array}$ & 0,08 & $\begin{array}{c}89,3 \pm \\
7,5\end{array}$ & 0,09 & $\begin{array}{c}88,1 \pm \\
6,5\end{array}$ & 0,08 & $\begin{array}{c}84,1 \pm \\
7,0\end{array}$ & 0,09 & $\begin{array}{c}82,2 \pm \\
6,9\end{array}$ & 0,09 & $\begin{array}{c}77,3 \pm \\
7,2\end{array}$ & 0,10 \\
\hline \multicolumn{13}{|c|}{ Медь } \\
\hline 1,0 & $\begin{array}{c}76,4 \pm \\
5,0\end{array}$ & 0,07 & $\begin{array}{c}62,2 \pm \\
4,0\end{array}$ & 0,07 & $\begin{array}{c}65,7 \pm \\
4,3\end{array}$ & 0,07 & $\begin{array}{c}70,3 \pm \\
4,6\end{array}$ & 0,07 & \begin{tabular}{|c|}
$72,3 \pm$ \\
4,7
\end{tabular} & 0,07 & $\begin{array}{c}74,2 \pm \\
5,5\end{array}$ & 0,08 \\
\hline
\end{tabular}




\begin{tabular}{|c|c|c|c|c|}
\hline ISRA (India) & $=1.344$ & SIS (USA) & ICV (Poland) & $=6.630$ \\
\hline ISI (Dubai, UAF & $=0.829$ & РИНЦ $($ Russia $)=0.179$ & PIF (India) & $=1.940$ \\
\hline GIF (Australia) & $=0.564$ & ESJI (KZ) & & \\
\hline IF & $=1.500$ & SJIF $($ Morocco $)=\mathbf{2 . 0 3 1}$ & & \\
\hline
\end{tabular}

\begin{tabular}{|c|c|c|c|c|c|c|c|c|c|c|c|c|}
\hline 1,5 & \begin{tabular}{|c|}
$80,5 \pm$ \\
5,2 \\
\end{tabular} & 0,07 & $\begin{array}{c}97,3 \pm \\
5,4\end{array}$ & 0,06 & $\begin{array}{c}96,3 \pm \\
5,4\end{array}$ & 0,06 & $\begin{array}{c}93,3 \pm \\
5,2 \\
\end{array}$ & 0,06 & $\begin{array}{c}84,4 \pm \\
5,5 \\
\end{array}$ & 0,07 & $\begin{array}{c}85,5 \pm \\
6,3\end{array}$ & 0,08 \\
\hline 2,0 & \begin{tabular}{|c|}
$87,3 \pm$ \\
5,7 \\
\end{tabular} & 0,07 & $\begin{array}{l}94,1 \pm \\
5,2\end{array}$ & 0,06 & $\begin{array}{c}94,4 \pm \\
5,3 \\
\end{array}$ & 0,06 & $\begin{array}{c}92,1 \pm \\
5,1\end{array}$ & 0,06 & $\begin{array}{c}83,2 \pm \\
5,4 \\
\end{array}$ & 0,07 & $\begin{array}{c}84,3 \pm \\
6,3\end{array}$ & 0,08 \\
\hline 2,5 & \begin{tabular}{|c|}
$86,2 \pm$ \\
5,6 \\
\end{tabular} & 0,07 & $\begin{array}{c}89,1 \pm \\
5,8 \\
\end{array}$ & 0,07 & $\begin{array}{c}88,4 \pm \\
5,7 \\
\end{array}$ & 0,07 & $\begin{array}{c}85,2 \pm \\
5,5 \\
\end{array}$ & 0,07 & $\begin{array}{c}80,3 \pm \\
5,2 \\
\end{array}$ & 0,07 & $\begin{array}{c}83,3 \pm \\
7,0 \\
\end{array}$ & 0,09 \\
\hline \multicolumn{13}{|c|}{ Кадмий } \\
\hline 1,0 & \begin{tabular}{|c|}
$72,7 \pm$ \\
5,4 \\
\end{tabular} & 0,08 & $\begin{array}{c}62,2 \pm \\
4,6 \\
\end{array}$ & 0,08 & $\begin{array}{c}65,9 \pm \\
4,9 \\
\end{array}$ & 0,08 & \begin{tabular}{|c|}
$70,1 \pm$ \\
5,2 \\
\end{tabular} & 0,08 & \begin{tabular}{|c|}
$72,8 \pm$ \\
5,4 \\
\end{tabular} & 0,08 & $\begin{array}{c}74,3 \pm \\
6,2 \\
\end{array}$ & 0,09 \\
\hline 1,5 & \begin{tabular}{|c|}
$79,1 \pm$ \\
5,9 \\
\end{tabular} & 0,08 & $\begin{array}{c}93,0 \pm \\
6,0\end{array}$ & 0,07 & $\begin{array}{c}93,1 \pm \\
6,0\end{array}$ & 0,07 & $\begin{array}{c}93,3 \pm \\
6,1\end{array}$ & 0,07 & $\begin{array}{c}84,6 \pm \\
6,3\end{array}$ & 0,08 & $\begin{array}{c}85,3 \pm \\
7,1\end{array}$ & 0,09 \\
\hline 2,0 & \begin{tabular}{|c|}
$83,0 \pm$ \\
6,2 \\
\end{tabular} & 0,08 & $\begin{array}{c}93,1 \pm \\
6,0\end{array}$ & 0,07 & $\begin{array}{c}92,3 \pm \\
6,0 \\
\end{array}$ & 0,07 & $\begin{array}{c}91,3 \pm \\
5,9\end{array}$ & 0,07 & $\begin{array}{c}83,5 \pm \\
6,2\end{array}$ & 0,08 & $\begin{array}{c}84,1 \pm \\
7,8\end{array}$ & 0,10 \\
\hline 2,5 & $\begin{array}{c}82,1 \pm \\
6,9 \\
\end{array}$ & 0,09 & $\begin{array}{c}84,7 \pm \\
6,3 \\
\end{array}$ & 0,08 & $\begin{array}{c}88,2 \pm \\
6,5 \\
\end{array}$ & 0,08 & $\begin{array}{c}87,1 \pm \\
6,5 \\
\end{array}$ & 0,08 & $\begin{array}{c}82,2 \pm \\
6,1 \\
\end{array}$ & 0,08 & $\begin{array}{c}81,2 \pm \\
7,5 \\
\end{array}$ & 0,10 \\
\hline
\end{tabular}

Частота низкочастотного УЗ - 22 кГи, частота высокочастотного УЗ - 1 МГц. Время воздействия УЗ - 2 мин.

В табл. 5 приведены сравнительные результаты определения свинца, меди и кадмия в сахаре с использованием при пробоподготовке одновременного воздействия УЗ высокой и низкой частот, УЗ только одной низкой частоты и стандартным методом после сухой минерализации. Лучшие метрологические характеристики результатов анализа были получены при использовании одновременного воздействия УЗ высокой и низкой частот (табл.5).
В основе большей эффективности двухчастотного воздействия УЗ по сравнению с У3 одной частоты лежат особенности образования и схлопывания кавитационных пузырьков. Во время действия двухчастотного УЗ возрастает количество малых сферических пузырьков, которые в отличие от больших деформационных пузырьков, более эффективно интенсифицируют данные процессы [8].

Таблица5

\section{Результаты определения содержания свинца, меди и кадмия в сахаре и} продуктах на его основе $(n=6, P=0,95)$

\begin{tabular}{|c|c|c|c|c|c|c|c|}
\hline \multirow{3}{*}{$\begin{array}{c}\text { Наименование } \\
\text { продукта }\end{array}$} & \multirow{3}{*}{$\begin{array}{c}\text { Введено Pb, } \\
\mathrm{Cu}, \mathrm{Cd} \text { по } \\
\text { мг/кг }\end{array}$} & \multicolumn{6}{|c|}{ Найдено микроэлементов (ĉ, мг/кг); Sr } \\
\hline & & \multicolumn{2}{|c|}{$\mathrm{Pb}$} & \multicolumn{2}{|c|}{$\mathrm{Cu}$} & \multicolumn{2}{|l|}{$\mathrm{Cd}$} \\
\hline & & $\hat{\mathrm{c}} \pm \varepsilon$ & $\mathrm{Sr}$ & $\hat{\mathrm{c}} \pm \varepsilon$ & $\mathrm{Sr}$ & $\hat{\mathrm{c}} \pm \varepsilon$ & $\mathrm{Sr}$ \\
\hline \multicolumn{8}{|c|}{$\begin{array}{c}\text { Использовано одновременное воздействие УЗ частотой } 22 \text { кГц и1 МГц, интенсивностью } 2,0 \text { и } 2,5 \text { Вт/см }{ }^{2} \\
\text { соответственно на протяжении } 2 \text { мин }\end{array}$} \\
\hline \multirow[t]{2}{*}{ Caxap } & 0 & $0,30 \pm 0,02$ & 0,07 & $0,25 \pm 0,01$ & 0,06 & $0,005 \pm 0,001$ & 0,087 \\
\hline & 0,100 & $0,39 \pm 0,03$ & 0,08 & $0,35 \pm 0,02$ & 0,06 & $0,103 \pm 0,005$ & 0,056 \\
\hline \multirow{2}{*}{$\begin{array}{r}\text { Напиток } \\
\text { «ранж» }\end{array}$} & 0 & $0,38 \pm 0,03$ & 0,08 & $0,29 \pm 0,02$ & 0,06 & $0,005 \pm 0,001$ & 0,089 \\
\hline & 0,100 & $0,46 \pm 0,03$ & 0,08 & $0,38 \pm 0,02$ & 0,06 & $0,105 \pm 0,006$ & 0,063 \\
\hline \multirow{2}{*}{$\begin{array}{r}\text { Напиток } \\
\text { «Вишня» }\end{array}$} & 0 & $0,31 \pm 0,02$ & 0,08 & $0,23 \pm 0,01$ & 0,06 & $0,003 \pm 0,001$ & 0,091 \\
\hline & 0,100 & $0,41 \pm 0,03$ & 0,08 & $0,32 \pm 0,02$ & 0,06 & $0,103 \pm 0,006$ & 0,064 \\
\hline \multirow{2}{*}{$\begin{array}{c}\text { Напиток } \\
\text { «Лимонный» }\end{array}$} & 0 & $0,23 \pm 0,02$ & 0,08 & $0,22 \pm 0,01$ & 0,06 & $0,004 \pm 0,001$ & 0,090 \\
\hline & 0,100 & $0,32 \pm 0,02$ & 0,08 & $0,32 \pm 0,02$ & 0,06 & $0,104 \pm 0,007$ & 0,067 \\
\hline \multicolumn{8}{|c|}{ Использовано воздействие УЗ частотою 22 кГц, интенсивностью 12 Вт/см² на протяжении 5 мин [6] } \\
\hline \multirow[t]{2}{*}{ Caxap } & 0 & $0,29 \pm 0,02$ & 0,09 & $0,25 \pm 0,02$ & 0,08 & $0,004 \pm 0,001$ & 0,107 \\
\hline & 0,100 & $0,38 \pm 0,03$ & 0,10 & $0,33 \pm 0,02$ & 0,08 & $0,102 \pm 0,009$ & 0,096 \\
\hline \multirow{2}{*}{$\begin{array}{r}\text { Напиток } \\
\text { «ранж» }\end{array}$} & 0 & $0,37 \pm 0,03$ & 0,09 & $0,29 \pm 0,02$ & 0,08 & $0,005 \pm 0,001$ & 0,105 \\
\hline & 0,100 & $0,45 \pm 0,04$ & 0,10 & $0,37 \pm 0,03$ & 0,08 & $0,101 \pm 0,009$ & 0,094 \\
\hline \multirow{2}{*}{$\begin{array}{r}\text { Напиток } \\
\text { «Вишня» }\end{array}$} & 0 & $0,31 \pm 0,03$ & 0,09 & $0,22 \pm 0,02$ & 0,08 & $0,003 \pm 0,001$ & 0,109 \\
\hline & 0,100 & $0,40 \pm 0,04$ & 0,10 & $0,31 \pm 0,02$ & 0,08 & $0,102 \pm 0,009$ & 0,095 \\
\hline \multirow{2}{*}{$\begin{array}{c}\text { Напиток } \\
\text { «Лимонный» }\end{array}$} & 0 & $0,22 \pm 0,02$ & 0,09 & $0,21 \pm 0,02$ & 0,08 & $0,004 \pm 0,001$ & 0,102 \\
\hline & 0,100 & $0,31 \pm 0,03$ & 0,10 & $0,31 \pm 0,02$ & 0,08 & $0,102 \pm 0,009$ & 0,091 \\
\hline
\end{tabular}




\begin{tabular}{|c|c|c|c|c|c|c|}
\hline Impact Factor: & $\begin{array}{l}\text { ISRA (India) } \\
\text { ISI (Dubai, UAF } \\
\text { GIF (Australia) } \\
\text { JIF }\end{array}$ & $\begin{array}{l}=1.344 \\
=0.829 \\
=0.564 \\
=1.500\end{array}$ & $\begin{array}{l}\text { SIS (USA) = } \\
\text { PUHЦ (Russia) } \\
\text { ESJI (KZ) = } \\
\text { SJIF (Morocco) }\end{array}$ & $\begin{array}{l}=0.912 \\
=0.179 \\
=1.042 \\
=2.031\end{array}$ & $\begin{array}{l}\text { ICV (Poland) } \\
\text { PIF (India) }\end{array}$ & $\begin{array}{l}=6.630 \\
=1.940\end{array}$ \\
\hline
\end{tabular}

\begin{tabular}{|c|c|c|c|c|c|c|c|}
\hline \multirow{2}{*}{ Сахар } & 0 & $0,28 \pm 0,03$ & 0,12 & $0,24 \pm 0,03$ & 0,11 & $0,004 \pm 0,001$ & 0,123 \\
\cline { 2 - 7 } & 0,100 & $0,37 \pm 0,04$ & 0,12 & $0,32 \pm 0,03$ & 0,11 & $0,098 \pm 0,103$ & 0,114 \\
\hline Напиток & 0 & $0,36 \pm 0,04$ & 0,12 & $0,28 \pm 0,03$ & 0,11 & $0,005 \pm 0,001$ & 0,121 \\
\cline { 2 - 7 } «Оранж»к & 0,100 & $0,44 \pm 0,05$ & 0,12 & $0,36 \pm 0,04$ & 0,12 & $0,099 \pm 0,011$ & 0,115 \\
\hline Напиток & 0 & $0,31 \pm 0,03$ & 0,12 & $0,21 \pm 0,02$ & 0,11 & $0,003 \pm 0,001$ & 0,127 \\
\cline { 2 - 7 } «Вишня» & 0,100 & $0,38 \pm 0,04$ & 0,12 & $0,30 \pm 0,03$ & 0,11 & $0,955 \pm 0,108$ & 0,122 \\
\hline Напиток & 0 & $0,20 \pm 0,02$ & 0,12 & $0,20 \pm 0,02$ & 0,12 & $0,004 \pm 0,001$ & 0,120 \\
\cline { 2 - 7 } «Лимонный» & 0,100 & $0,28 \pm 0,03$ & 0,12 & $0,28 \pm 0,03$ & 0,12 & $0,101 \pm 0,011$ & 0,117 \\
\hline
\end{tabular}

Анализировали сухие напитки производства Славянской соледобывающей компании.

Правильность методик проверяли методом добавок на растворах сахара и различных напитках. Также, те же пробы анализировались стандартным атомно-абсорбционным методом после сухой минерализации и методом с использование УЗ одной частоты (табл.5 ).

Выводы. Разработана экспрессная методика определения свинца, меди и кадмия в сахаре и продуктах на его основе. Показано, что предварительная обработка УЗ высокой и низкой частот анализируемых растворов приводит к повышению чувствительности и экспрессности определения, улучшению метрологических характеристик результатов анализа. Экспериментально и на основе анализа литературных данных установлено, что в основе повышения экспрессности анализа лежит протекание соответствующих звукохимических реакций, приводящих к переводу соединений свинца, меди и кадмия в более кинетически лабильные соединения.

\section{References:}

1. (1986) GOST 26927-GOST 26935 - 86 Syr'e i produkty pishchevye. Metody opredeleniya toksichnykh elementov. M.: Gos.komitet SSSR po standartam.-1986.- 85 p.

2. Andreia R (2015) Chemical safety of children's play paints: Focus on selected heavy metals / R. Andreia, P. Edgar, V.S. Manuela, A.A. Agostinho // Microchemical Journal. - 2015. Vol. 118. - pp. 203-210.

3. Frans van den Berg (2013) Process Analytical Technology in the food industry / Frans van den Berg, Christian B. Lyndgaard, Klavs M. Sorensen, Soren B. Engelsen // Trends in Food Science \& Technology. - 2013. - Vol. 31. pp. 27-35.

4. Fumes BH (2015) Recent advances and future trends in new materials for sample preparation / B. H. Fumes, M. R. Silva, F.N. Andrade, C.E. Nazario, F. M. Lancas // TrAC Trends in Analytical Chemistry. - 2015. - Vol. 71. - pp. 9-25.

5. (1996) GOST 30178-96 Syr'e i produkty pishchevye. Atomno-absorbtsionnyy metod opredeleniya toksichnykh elementov.

6. (1999) GOST R 51301-99. Pishchevye produkty i prodovol'stvennoe syr'e. Metody inversionno-vol'tamperometricheskogo analiza na soderzhanie toksichnykh elementov (kadmiya, svintsa, medi, tsinka).- Gosstandart Rossii, 1999.-145 p.

7. (2000) MUK 4.1.985-00 Opredelenie soderzhaniya toksichnykh elementov $\mathrm{v}$ pishchevykh produktakh i syr'e. Metodika avtoklavnoy probopodgotovki

8. Khavezov I, Tsalev D (1983) Atomnoabsorbtsionnyy analiz. - L.: Khimiya, 1983. $144 \mathrm{p}$.

9. Chmilenko FA (1998) Atomno-absorbtsionnoe opredelenie toksichnykh elementov $\mathrm{v}$ sakhare $\mathrm{i}$ produktakh na ego osnove $\mathrm{s}$ ispol'zovaniem ul'trazvukovoy probopodgotovki / F. A. Chmilenko, L. V. Baklanova // Zhurn. analit. khimii. - 1998. - T. 53, № 8. - pp. 891-894.

10. Baklanov OM, Avdeenko AP, Chmilenko F.O., Baklanova LV (2011) Analitichna khimiya kukhonnoï soli ta rozsoliv: MonografiyaKramators'k: Vid. DDMA, 2011. - 282 p.

11. Margulis MA (1986) Zvukokhimicheskie reaktsii i sonolyuminestsentsiya. - Moscow: Khimiya, 1986. - 288 p. 